\title{
A Construal Model Perspective on Discourse Coherence
}

\author{
Hongyan Yang ${ }^{1}$ \\ ${ }^{1}$ School of Foreign Languages, Leshan Normal University, Leshan, China \\ Correspondence: Hongyan Yang, School of Foreign Languages, Leshan Normal University, Leshan, China. Tel: \\ 86-135-4190-8233. E-mail: 10553891@qq.com
}

Received: August 24, 2015 Accepted: September 20, 2015 Online Published: September 21, 2015

doi:10.5539/elt.v8n10p133 URL: http://dx.doi.org/10.5539/elt.v8n10p133

\begin{abstract}
Discourse coherence is a common phenomenon in linguistic studies, and plays an important role in discourse analysis. As a common and extremely important type of language phenomena, discourse coherence has drawn more and more scholars' attention, but they emphasis on partial discourse coherence, paying a little attention to holistic coherence. The paper is an attempt to explore the mechanism of discourse coherence within the framework of Mental-Model based stereotypical relation theory, and proves that it is the rule of similarity and proximity that leads to the discourse coherence.
\end{abstract}

Keywords: discourse coherence, generative holistic, Mental-Model Based stereotypical relation theory, the rule of Similarity and Proximity

\section{Introduction}

\subsection{The Definition of Coherence}

Generally speaking, the appearance of Halliday and Hasan's work Cohesion in English (1976) marks the establishment of cohesion theory. Halliday and Hasan's cohesion theory is a great step to the analysis of discourse, but they haven't given an exact definition of coherence. As for the nature of coherence, there exist two points of view: social phenomenon and psychological phenomenon. Some linguists agree that coherence is just a kind of linguistic or social phenomenon. They treat language as a social signal and the use of language is social act. They regard coherence as semantic or functional relations by the means of sentences and utterance. (Beaugrand \& Dressler, 1981; Stubbs, 1983).

Others, especially Givon (1995), think coherence is a mental process. They have done research in the light of psychological knowledge (Zhu \& Yan, 2001). Givon (1995) points out that coherence does not happen in external text, but psychological text.

\subsection{Previous Study on Discourse Coherence}

Recently, there have been numerous researches on discourse coherence. Halliday and Hasan (1976) pointed out the importance of coherence in a text and discussed the relation between cohesive and coherence. Finally, he made conclusion that register and cohesion are basic conditions for textual coherence.Van Dijk also holds the same idea of coherence with Halliday and Hasan's theory. He also pointed out four types of coherence and two conditions of connection or connectedness. In de Beaugrande and Dressler put more attention on cohesive devices than Halliday and Hasan. Compared with Halliday \& Hasan and Beaugrande and Beaugrande and Dressler focus on the function of text, George Yule hold totally different kinds of view that to interpret a text relies on reader's psychological point of view instead of the linguistic connections. That's to say, whether a text with or without linguistic connections between elements, readers can get the correct meaning of a text by the means of psychological analysis. Widdowson think that coherence is a kind of pragmatic concept, cohesion was regarded as a link word to connect sentences and semantics. Coherence is being used to perform instead of being overtly linked. Givon give more systematical explanation of coherence, he regards coherence as a the result of produce and interprets the text, rather than a property of the text. Mann and Thompson do research on discourse on the basis of their Rhetorical Structure Theory (RST) (1992). This theory agrees that a discourse consists of functionally significant parts and each of them has their own functions. 
Undoubtedly, the previous studies have their own contributions for linguistic research. Nevertheless, each theory has its own shortcomings. The theoretical framework of Halliday and Hasans theory of cohesion and coherence is firmly established. However, they fail to consider mental aspect in their study. Over-emphasis on the effect of cohesive device is bad for forming of the powerful theory. While Van Djik neglect the non-text factors like, readers' education background, social background, traditions, beliefs and so on. Therefore, It is necessary for us to find a persuasive method to analyze discourse coherence. In order to find out the answer, we tend to combine advantages of previous theories to analyze the deep process of discourse coherence as the case of context , semantic and mental activity are evitable aspects of discourse coherence. Therefore, it' high time for us to put forwards a feasible and effective way to analyze discourse coherence the internal mechanism of coherence.

\subsection{Necessity of the Study}

This paper attempts to analyze discourse coherence from MM-based Construal Model to figure out the mechanism of different types of discourse coherence. MM-Based Construal Model both focus on text and reader's minds, which is closely related to our context, environment, culture, belief and social background and so on. We hope that we can apply this newly proposed MM-based Construal Model to explain the mechanism of different types of discourses, and prove its power of explanation in discourse coherence analysis.

\section{Theoretical Framework of the Study}

\subsection{Cognitive Model}

The notion of Cognitive model, which is on the basis of embodiment philosophy and the theory of prototype, was first proposed by a famous linguistic scholar Lakoff (13-538). He holds that CM can be embodied, which is constructed from interactions between human beings and the world. CM also is integrated; it is not only constructed by each part, but also can be regarded as an integrated system. At the same time, CM is immanent; it is a kind of cognitive alternatives. Context means that information related with mental phenomenon and deposited in memory. The information infers background information and can be understood in discourse process. CM is certain a knowledge-related representation about a certain situation and context existing in human mind. It is the basic part of category and concept.

\subsection{MM-Based Construal Model}

MM-Based Construal Model is a new perspective of discourse analysis, which was established on the basis of Professor Xu shenghuan's MM-Based Explicature-Implicature Reasoning Framework (1995) and generative holistic construal.

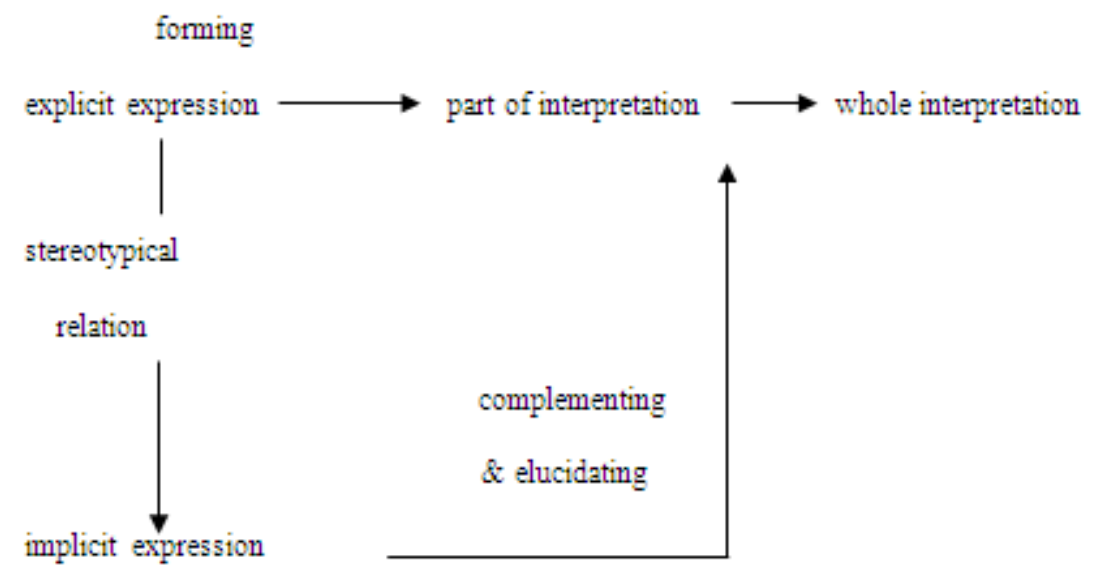

Figure 1. MM-Based explicature-implicature reasoning framework

Professor Xu's model-based pragmatic reasoning $(2005,2006 \mathrm{a}, 2006 \mathrm{~b}, 2007)$ the basic viewpoints of daily language use in pragmatics, is different from the principle-approach paradigm. This theory takes into consideration the achievements in researches of human cognitive faculties done by cognitive psychology, adopting a standpoint of psychological reality and argues that pragmatic reasoning is an utterance process caused 
by downward causation. In view of the hypothesis of cognitive continuum, the findings and conclusions of the study would also provide a working hypothesis for the study of daily language use.

\subsection{Holistic Construal Theory}

we give an introduction of cognitive model, which holds corresponding standpoint that we should regard the world as an integrity, Therefore, this paper presents a hypothesis that discourse coherence results from the audience's holistic construal of the discourse. The holistic construal is the default knowledge of the audience when approaching a discourse. This approach is characteristic of two cognitive processes: one is responsible for indefinite reference solution and the other is identifying the discourse relation connecting sub-discourses on the basis of the argument for the optimal discourse coherence. Conversational implicature is viewed as a by-product of the holistic construal.

From the perspective of cognition, the nature of coherence is sub-discourse activating stereotypical relations, it reasonably collocates and forms an integer part. Under the hypothesis of integrity holism, the Cognitive subject collocates parts for the service of whole discourse. In other words, major whole and minor parts have close relation; minor parts have no meaning without major whole; To the audience, discourse comprehension not only refers to holistic promise, but also considers well-formed discourse tendency. To recognize objects, Cognitive subject does not automatically reflect cognitive objects, but put fragmentary object together under the guidance of well- formedness. Each word finds its certain meaning in each sentence, each sentence gets its meaning in the context, and each discourse apprehends meaning in context. That is to say, context plays a crucial role in discourse analysis. Besides distinctive cohesive devices, reasonable interference corresponds closely with cognitive subject' experience. The closer to cognitive subject's experience the features of discourse object is, the better the structure of discourse is. Well-formedness requires two basic requirements: One is holistic promise, and the other is accessibility of experience.

The choices of meaning relation of two discourses decide that cognitive subjects have inform-related judgment mental tendency. We name it for discourse construal format. Formed by definition, Discourse construal format contains many kinds of relations, such as interlocution relation, condition relation, time relation, contrast relation and so on. All of those relations manifest through semantic relation, not by the cohesive devices. By cognitive economic rule, the most common cognitive format is to find the most corresponding "low-consumed" principle for information process.

Therefore, holistic construal theory refers to the rule from holistic perspective instead of individual items. As a holistic system, generation and evolvement of language would represent the basic features depicted by generative holism. Generative holism holds that the relation between the whole and the parts is not reduction but a relation between the major whole and minor wholes. The meanings of the minor wholes are indeterminate and influenced by the major whole. The major environment is represented by a construction which can determine the semantic construal of its parts via proximate relation in the minor environment; the part environment comes after major environment.

\subsection{The Preconditions of Coherence}

In order to strengthen the application of this new model, several preconditions of coherence model are requested.

\subsubsection{The Expectation of Discourse Coherence}

The construction of discourse is the result of rational action. That is to say, the participants are required to be cooperative and rational. Readers have an expectation of discourse coherence. In constructing a discourse, in line with the linear order of the discourse and based on the stereotypical relations triggered by information from the preceding sub-discourse, the listener will first construct a mental model, and hence induce a certain expectations of the successive discourse. If the expectation is satisfied, then this discourse would be regarded as a coherent discourse, if not, it is not a coherent one.

Corresponding with the holistic construal theory, the expectation of discourse is very essential. From the perspective of psychology, the essence of discourse is to encourage stereotypical relations through explicit information. Relative relation in human mind constructs implicit information. According to the view of holistic generation theory, there is no state and unchangeable objects in the world, and there is no whole without parts. Discourse is regarded as meaning coherent discourse. 


\subsubsection{From Generative Holistic Perspective}

This paper represents a hypothesis that discourse is comprehensible and coherent. It is a comprehensible discourse which means audience make a reasonable holistic construal to construct discourse coherence. In some discourses, the cohesion markers are obvious; consequently, it is easier for audience to infer the underlying meaning of a discourse. Nevertheless, some cohesion markers are inconspicuous and even inexistent, so the audience has to interfere the certain meaning on the basis of sub-discourses, through stereotypical relations. Each word gets its meaning under the limitation of sentences. Each sentence has its own meaning in a context.

Based on Professor Xu' framework of MM-Based Pragmatic Reasoning Hypothesis, this paper tries to set up a mechanism of cognitive reasoning of discourse, which adopt the essence of terminology and methodology. Meanwhile, the process should include the key procedure of process of interpretation discourse coherence.

Thus, to combine the shinning lines of MM-Based Explicature-Implicature Reasoning Framework and generative holism, we put forwards a new construal model like as follows:

The key procedure of our mechanism is the positive-negative continuum of proximity and similarity of a certain category:

$\mathrm{Cn}+\mathrm{x}, \mathrm{Cn}, \ldots \mathrm{C} 3, \mathrm{C} 2, \mathrm{C} 1, \mathrm{C}, \mathrm{C}-1, \mathrm{C}-2, \ldots(\mathrm{C}-(\mathrm{n}+\mathrm{x}) \approx-\mathrm{C}-(\mathrm{n}+\mathrm{x})), \ldots-\mathrm{C}-2,-\mathrm{C}-1,-\mathrm{C},-\mathrm{C} 1,-\mathrm{C}-2, \ldots-\mathrm{Cn},-\mathrm{Cn}+\mathrm{x}$

(From $\mathrm{Cn}+\mathrm{x}$ to $\mathrm{Cl}$ is positive continuum of proximity; $\mathrm{C}$ is the neutral one

From $C-1$ to $-C n+x$ is negative continuum of Proximity)

Figure 1 Theoretical Mechanism of Discourse Construal Model

A Category's Positive-Negative Continuum of Proximity

$\mathrm{A}:(\mathrm{E}) \rightarrow \mathrm{B}:(\mathrm{F})$
A: an event 1
B: an event ${ }_{2}$
E: a stage of event A.
F: a stage of event B

Once we mention $\mathrm{E}$ in an event $\mathrm{A}$, we can imagine $\mathrm{F}$ in an event $\mathrm{B}$

$$
\underline{\mathrm{R}_{-\mathrm{N}} \ldots \mathrm{R}_{-4}, \mathrm{R}_{-3}, \mathrm{R}_{2}, \mathrm{R}_{1}, \mathrm{R}_{0}, \mathrm{R}_{1}, \mathrm{R}_{2}, \mathrm{R}_{3}, \mathrm{R}_{4} \ldots \mathrm{R}_{\mathrm{N}}}
$$

Figure 2. A positive-Negative Continuum of similarity of category

A coherent discourse should follow three rules

(1) The whole discourse can be divided into several sub-discourses. The internal relation of a text was interrelated by stereotypy (similarity and proximity continuums). This part was viewed as explicature or dependency part. The auther's feelings or thought is a kind of stereotypical model, which was named as implicature or autonomy part.

(2) According to the explicature part, reader can derive stereotypical model by the means of similarity and proximity rule. Meanwhile, stereotypical model, the implicature part, also can counter for the explicature. That is to say, stereotypical continuums, play an intermediate role in the readers' construal process.

(3) The combination of explicature part, initial condition and boundary condition form the whole meaning of discourse. In readers' mind, the initial condition and boundary condition lead readers to reason the whole text to the opposite direction, which ensures readers' reasoning process is feasible and reasonable. Thus, a text-based a stereotypical model can be established in the reader's mind. that to say, although mountainous data will dash into in reader's mind, reader can quickly get the author's meaning and feeling according to reader's, reading skills, education background culture, belief, social background and so on.

\subsection{The Working Definition of Coherence for the Study}

At present, the concept of coherence in discourse analysis has witnessed a history of many decades of research. 
Different people holds different point of view towards the definition of coherence. Some scholars view it as a property of text, while others view it as a product or process of discourse reasoning. But the basic aim of coherence research is to explore the mechanism of coherence and the factors which will contribute to the understanding process of discourse from mental activity perspective. For the sake of construction of a relative full notion of coherence, a new notion of coherence comes out. We think coherence is the relationship between the discourse and the stereotypical mental model, both of which are under the restriction of whole meaning of discourse. If the discourse can be inferred from the mental model by means of Similarity and Proximity Continuums, we regard it as coherence discourse.

\section{Application of the Newly Proposed Construal Model of Discourse Coherence}

\subsection{The Application of Construal Model on Discourse with Obvious Cohesive Devices}

\subsubsection{Incoherent Discourses with Cohesive Device}

One of the specific examples is like this:

Example (1)

(1)I bought a Ford. (2)A car in which President Wilson rode down the Champs Elysees was black. (3)Black English has been widely discussed. (4)The discussions between the presidents ended last week. (5)A week has seven days. (6)Every day I feed my cat. (7) The cat in on the mat. (8) Mat has three letters. (王寅, 2007: 355)

Although each sentences has obvious cohesive devices, the writer failed to express his/her implicit meaning to the readers. Obviously, "Ford" in the clause (1) has no relation to "a car" in clause (2).

Obviously, " a Ford" in the clause (1) and "A car" and in clause (2)does not refer to the same object. According to the dependent part "A Ford", we search stereotypical relation (proximity and similarity) between them which is not related. Meanwhile, "black" in clause(2) stands for color, on the contrary, "black" in "black English" refers to a kind of language which was widely used in the black community. The same word in different sentences holds different meanings. Obviously, we can find some relation from the stereotype formally, however, due to there is no logical relation( $\mathrm{R})$ to govern the whole discourse, readers need to choose other way to reason the whole discourse on the basis of similarity and proximity in reader's mind, if not, the discourse is not a coherence one.

Example (2)

张大嫂有个女儿。男尊女卑的思想在中国尚未彻底消除。中国正在实现四个现代化。后现代主义是一种 文学思潮 (胡壮麟, 180.)

(Sister Zhang has a daughter. The traditional bias that men are superior to women has not been completely cleared yet in China. China is now on the way to realize the Four Modernizations. Post-modernism is a kind of literary trend of thought.)

The key point of this utterance is how to interpret“女儿”(daughter) and“女”(women); “现代化”(modernization) and “现代主义” (modernism). The two pairs do not construct logical relation, at the same time, the reader cannot make a downward causation as there is not an intention to pull the reader to seek in the mental model.

\subsubsection{Coherent Discourses with Coherent Device}

Example (3)

A: How did you think about the football match?

$\mathrm{B}$ : it is a wonderful gymnasium.

That is a coherent discourse. Here "it" refers to the "football match". Obviously it has coherent device. At the same time, A's intention that A wants to know what does B think of the performance is formed. The whole meaning of this discourse is formed named D. It pulls B to seek in his mental model of the degree of mood, the downward causation continuums may follow like as follows:

令人作呕的, 让人反感的, 让人失望的, 一般般, 还行, 好的, 精彩, ......

B makes his choice nice, which corresponds to B's mental model about the degree of performance's splendid.

3.2 Coherent Discourses without Cohesive Devices

Example (4) 
(one day, when a husband come back from work, his wife ask him )

A: 今天心情怎么样?

B: 还不错。

The key point to understand this utterance is to interpret “心情”(mood). First, we discover two cues in this utterance, that are “心情”(mood), and “还不错”. The initial condition is that the husband comes home from work and boundary condition is about the husband's mood, then we named D for the whole meaning of this discourse. It causes downward causation and pulls the husband to seek in his mental model of the degree of mood, the downward causation goes like as follows,

坏透了, 相当不好, 很不好, 不太好, 一般......, 好, 相当好, 有点好

Finally, the listener makes his conclusion reasonably through context analysis. We regard this discourse as coherent one. The process of this discourse can be showed like this:

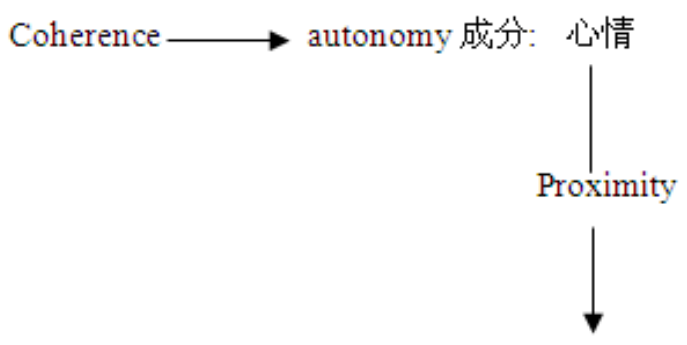

dependency 成分: 还不错

This chart prove the role of proximity continuum in the process of discourse construal

$$
\text { /conf/ 心情好坏 } \mathrm{F}(\mathrm{n}+\mathrm{x}) \ldots \mathrm{F}-3, \mathrm{~F}-2, \mathrm{~F}-1, \mathrm{~F} 0, \mathrm{~F} 1, \mathrm{~F} 2, \mathrm{~F} 3 \ldots \mathrm{F}(\mathrm{n}+\mathrm{x})
$$

Although some discourses seem to be incoherent, they are coherent ones.Tthe only difference is that those coherent degrees are lower than others. Let's take two typical examples in coherence analysis.

Please look at the following two examples.

Example (5)

A: There's the telephone.

B: I'm in the bath.

A: OK (Widdowson, 1978)

Example (6)

A: Can you go to Edinburgh tomorrow?

B: B.E.A. pilots are on strike. (Widdowson, 1979)

In discourse (5), When A says that "there's the telephone" the underlying meaning is that A hopes B can answer the call. The key phrase in A is "a call is ringing" as the autonomy part, intention makes B to stimulate the mental model in B about the process to answer a phone, and search for the related information in the law of proximity. However, B did not choose a direct way to give the answer that he/she cannot answer the phone, no matter it is caused by any reasons.

Like discourse (5), Discourse (6) is also a coherent discourse. The initial part is that it is long distance from here to Edinburgh, so taking a plane is the only choice; the boundary condition is to take a plane. The whole intention of $\mathrm{A}$ is to make sure whether B is going to Edinburgh tomorrow. The downward causation was governed by the whole meaning of $\mathrm{D}$, which will push readers to seek the specific continuum of relevant category in their mental models to make sure the dialogue is coherent. Pilot is one part of the process of taking plane. Then B answered 
"B.E.A.pilots are on strike" which means that he is not going to Edinburgh tomorrow for this reason. This discourse seems not coherent one. As long as we analyze the situation carefully, we can find it is a true one. B takes a indirect way to express his schedule tomorrow. The process of construing this discourse can be viewed like this:

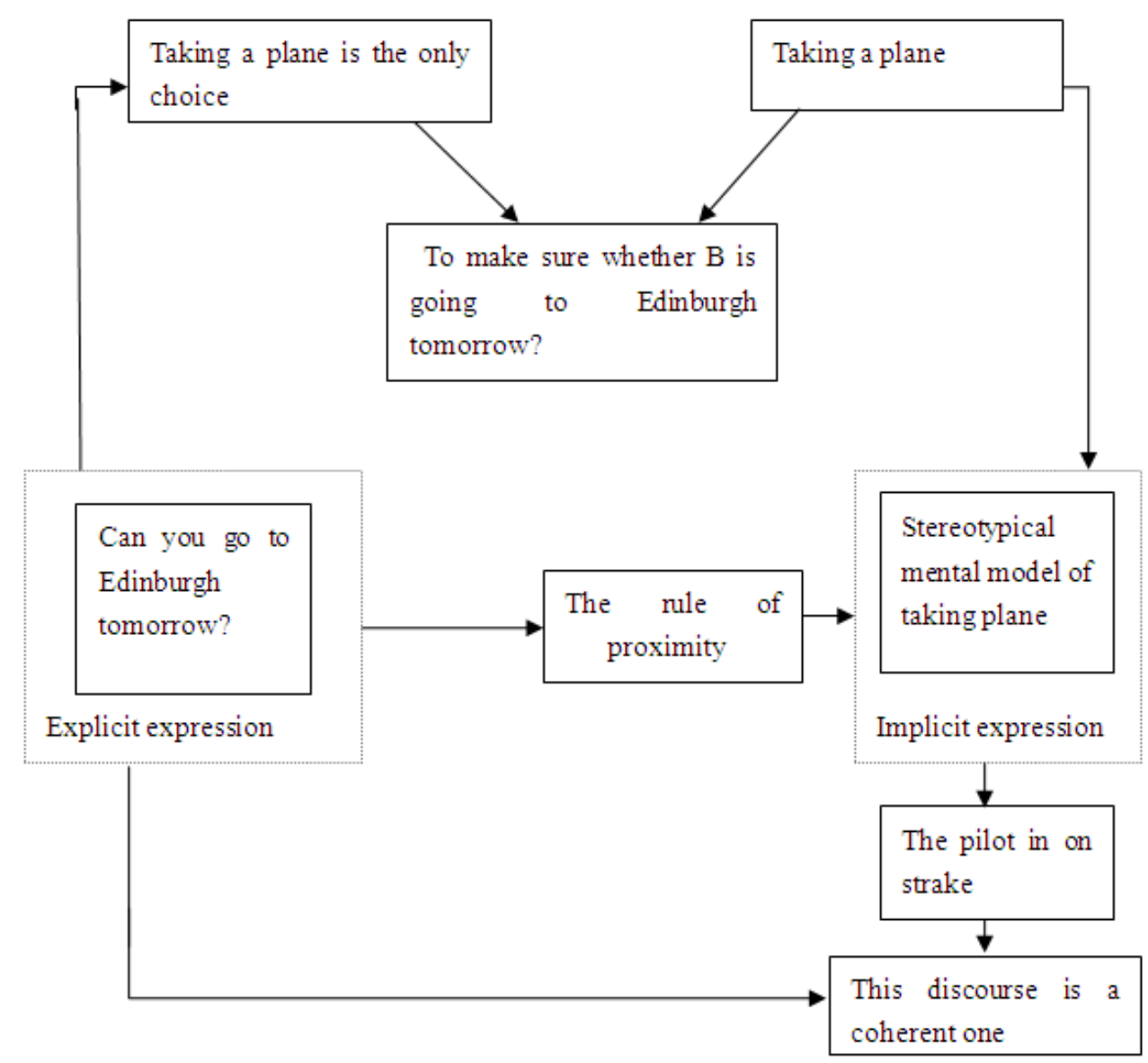

The law of proximity of "go to Edinburgh"

(1) to Buy ticket(booking office, booking clerk, other guests...), (2) to Prepare to park(clothes, gifts, data, luggage...), (3) to take taxi to the airport(the drive, get on the car, get off the car...), (4)to wait for the plane(checking desk, checking clerk, friends, guests, ... ), (5)people on a plane (e.g. pilot, Miss air, ....)

The process of going to Edinburgh involved several stages, which are related to each other. That is to say, once we mention "go to Edinburgh" the proximity entities are quickly formed in human mental model of "go to Edinburgh".

Let' look at the following three discourses.

Example (7)

News reporter: Do you think Anita Hill is lying?

Senator: Yes.

Example (8)

News reporter: Do you think Anita Hill is lying?

Senator: If someone sexually harassed me, I wouldn't follow them to another job or call them repeatedly on the phone. 
Example (9)

News reporter: Do you think Anita Hill is lying?

Senator: I love to eat crawfish bisque.

Obviously, the degree of coherence should like this, example (7)is the most coherent, (8)is less, and (9)is the least. Example 9) requires much inference on the part of the recipient. The coherence should be graded from text-external to text-internal factors and from the whole to the part. Coherence has hierarchy. There must be a whole meaning of a discourse to dominate the sub-discourses.

\section{Conclusion}

MM-Based Model Construal provides another alternative methods to analyze discourse coherence. From the discussion, we proposed a new construal model of discourse coherence analysis. It also empowers scholars to analyze discourse coherence from both text and readers' mental perspectives, which give a concrete mechanism of discourse coherence. Although it reveals the internal construal process of readers' mental process, it also has some limitations. First, the number and diversity of sampling are limited. Therefore, there is still room for us to check and analyze the power of construal model. Second, whether this new construal model can be applied into different languages still give us broad room to do research.

\section{References}

Brown, G., \& Yule, G. (1983). Discourse Analysis. Cambridge: Cambridge UniversityPress. http://dx.doi.org/10.1017/CBO9780511805226

Beaugrande, R., \& Dressler, W. (1981). An Introduction to Text Linguistics. London: Longman Press.

Halliday, M. A. K., \& Hasan, R. (1976). Cohesion in English. Beijing: Foreign Language Teaching and Research Press.

Hasan, R. (1984). Coherence and Cohesive harmony. In J. Flood, (Ed.), Understanding Reading Comprehension Delaware. International Reading Association.

Stubbs, M. (1983). Discourse Analysis. Oxford: Blackwell.

Givon, T. (1995). Coherence in Text vs Coherence in Mind. In Coherence in Spontaneous Text. Armstertam. John Benjamins Publishing Company. http://dx.doi.org/10.1075/tsl.31.04giv

Jingjing, C. (2007). A Note on the Production-Interpretation Mechanism of Irony. College of Foreign Languages Henan University.

Mann, W. C., \& Christian, M. I. M. M. (1991). Functions of Language in Two Frameworks, 3, 231-249.

Van. Dijk, T. A., \& Kintsch, W. (1983). Strategies of Discourse Comprehension. New York: Academic Press.

Van. Dijk, T. A. (1997). Discourse as Structure and Process. Discourse Studies: A Multi-disciplinary Introduction London: SAGE Publications.

Widdowson. H. (1978). Teaching Language as communication. Oxford: Oxford University Press.

Widdowson. H. G. (1979). Explorations in Applied Linguistics. Oxford University Press.

Wang, Y. (2007). Cognitive Linguistics. Shanghai Foreign Language Education Press.

Xu, S. (2002). Cognitvization and Stereotypical Relation: Stereotypical Relation Revisited. Journal of Foreign Languages.

$\mathrm{Xu}, \mathrm{S}$. (2006b). Proximity and Complementation: Studies of the Formation Mechanism of Idioms From Cognitive Point of View. Journal of Sichuan International Studies University.

Xu, S. (2007). Model-based Pragmatic Reasoning. Journal of Foreign Languages.

Xu, S. (2007a). Autonomy-Dependecy: An Analytical Framework for Utterance Producing. Foreign Language Research.

Xu, S. (2007b). A Note of Interrelating. Journal of PLA University of Foreign Languages.

Zhang, D. (2001). Discourse Coherence analysis. Foreign Language Teaching and Research.

Zhao, Y. (2001). An Introduction to Cognitive Linguistics. Shanghai, Shanghai Foreign Language Education 
Presss.

\section{Copyrights}

Copyright for this article is retained by the author(s), with first publication rights granted to the journal.

This is an open-access article distributed under the terms and conditions of the Creative Commons Attribution license (http://creativecommons.org/licenses/by/3.0/). 